\section{Microbiological, chemical-physical and sensory characteristics of Fabriano salami from pigs fed Oregano vulgaris extract}

\author{
Dino Miraglia, ${ }^{1}$ David Ranucci, ${ }^{1}$ \\ Massimo Trabalza-Marinucci, \\ Gabriele Acuti, ${ }^{1}$ Claudio Forte, ${ }^{2}$ \\ Michela Codini, ${ }^{3}$ Rossana Roila, ${ }^{1}$ \\ Raffaella Branciari ${ }^{1}$
}

${ }^{1}$ Department of Veterinary Medicine, University of Perugia; ${ }^{2}$ Institute for Experimental Veterinary Medicine of Umbria and Marche, Perugia; ${ }^{3}$ Department of Pharmaceutical Sciences, University of Perugia, Italy

\section{Abstract}

This study aimed at evaluating the effect of Oregano vulgaris extract supplementation of heavy pig diet on the microbiological, chemical-physical and sensory characteristics of Fabriano salami. Fabriano salamis were produced processing meat derived from pigs belonging to two dietary groups of 16 pigs each: CTRL group fed a commercial pelleted feed, and OR group fed the CTRL diet integrated with $0.2 \%$ of oregano extract. Ten salamis per group were collected at 0, 7, 20 and 45 days of ripening and analysed for total viable count, enumeration of Enterobacteriaceae, Enterococcus spp, coagulase negative and positive staphylococci, Lactobacillus spp., Lactococcus spp., presence of Salmonella spp. and Listeria monocytogens, $\mathrm{pH}$, water activity $\left(\mathrm{a}_{\mathrm{w}}\right)$ and colour (CIE L*a* $\mathrm{b}^{*}$ colour system). At the end of the ripening (day 45) chemical composition (AOAC, 1990), total antioxidant capacity $\left(\mathrm{ORAC}_{\mathrm{FL}}\right)$, thiobarbituric reactive substances (TBARS), total phenolic content (TPC) (Folin-Ciocalteu method) and consumer tests were performed. The integration of oregano extract in pig diets did not interfere with the microbial evolution, chemical composition, $\mathrm{pH}$ and $\mathrm{a}_{\mathrm{w}}$. After 20 days of ripening the OR salami were redder then CTRL samples, which were also yellower at the end of ripening. Furthermore, the diet has significantly improved the oxidative status, the polyphenolic content and antioxidant power in OR salami. The consumers gave a higher score to OR salami in informed condition.

\section{Introduction}

In the last few years, concerns over adverse health effects of synthetic additives such as synthetic antioxidants caused and increased consumers demand for food products containing natural ingredients. Synthetic antioxidants have long been used to delay quality deterioration in meat and meat products induced by oxidation processes, while in the recent years their use has been discouraged due to their potential genotoxic effects (Jiang Jaing et al., 2016). Therefore, the current industrial food trend has shifted towards different natural plant extract as sources of bioactive substance for food preservation (Burt, 2004; Zheng et al., 2001). Several studies demonstrated that extracts obtained from fruit, vegetables, spices and herbs such as rosemary, sage, oregano and other, thanks to their high content of phenolic compounds, exert high antioxidant activities able to improve oxidative stability in food (Akarpat et al., 2008; Burt, 2004; Huang et al., 2011; Srinivasan, 2014; Zheng et al., 2001). Naturals antioxidants are also included in animal diets for their positive effects on animal performance, health and welfare. Recently, several animal feeding strategies have been investigated to enhance nutritional value, improve the organoleptic properties and the health benefit of meat and meat products. Nieto et al. (2010) observed that dietary rosemary supplementation in pregnant ewes delayed the microbial growth, decreased the lipid oxidation and improved colour and odour of subsequent lamb meat during storage. Luciano et al. (2011) reported that a tannin enriched diet extended colour stability and increased total phenols content and antioxidant capacity of lamb meat. Moreover, Ranucci et al. (2015) obtained interesting results on cooked ham including oregano essential oil and sweet chestnut wood extract in pig diets. Products during storage showed an increased oxidative stability, antioxidant capacity and better values in colour scores but not modification were recorded for microbiological characteristics. However, despite several studies reported the effect of feeding natural antioxidants on meat characteristics, limited data on processed meat, such as salami, are available in literature.

Thus, the aim of the present study was to evaluate the influence exerted by oregano extract dietary supplementation in pigs on the microbiological profile, chemicalphysical characteristics and sensory properties of Fabriano salami.
Correspondence: Dino Miraglia, Department of Veterinary Medicine, University of Perugia, via San Costanzo 4, 06126 Perugia (PG), Italy. Tel: +39.075.5857932 - Fax: +39.075.5857932

E-mail: dino.miraglia@unipg.it

Key words: Oregano extract, Antimicrobial, Antioxidant, Consumer test, Salami.

Contributions: the authors contributed equally.

Conflict of interest: the authors declare no potential conflict of interest.

Received for publication: 13 July 2017.

Revision received: 13 October 2017.

Accepted for publication: 14 October 2017

This work is licensed under a Creative Commons Attribution-NonCommercial 4.0 International License (CC BY-NC 4.0).

(C) Copyright D. Miraglia et al., 2017

Licensee PAGEPress, Italy

Italian Journal of Food Safety 2017; 6:6906

doi:10.4081/ijfs.2017.6906

\section{Materials and Methods}

In this study, 32 Duroc $x$ Large White pigs, with an initial live weight of $35 \mathrm{Kg}$, were bred. At the beginning of the trial, the animals were divided into two experimental groups of 16 subjects each and fed with a commercial pelleted feed (CTRL) or the same feed supplemented with $0.2 \%$ of oregano (Origanum vulgaris L.) extract (OR). Both diets were isonitrogenous and isoenergetic and in finishing stage (from $120 \mathrm{Kg}$ live weight to slaughtering) were supplemented with $0.5 \%$ commercial source of conjugated linoleic acid (CLA) (LodeStar ${ }^{\mathrm{TM}}$ CLA, Berg + Schmidt GmbH \& Co., Hamburg, Germany). When the pigs reached a live weight of $170 \mathrm{Kg}$ were regularly slaughtered in a local slaughterhouse and the carcasses were transported to an industrial processing plant located in the province of Ancona (Central Italy) for the salamis production. The animal care procedures were in accordance with the European recommendations (European Parliament and the Council of the European Union, 2010) for the protection of animals used for scientific purposes. Fabriano salami was produced from meat derived from each dietary group (CTRL and OR) according to traditional procedures (Rea et al., 2005). Briefly, the mixture was prepared using refrigerated meat from pork shoulders (67\%) and scraps from thigh and loin processing (33\%). After grinding the mixture, loin lard $(10 \%$ of meat weight) cut into small cubes of $10 \mathrm{~mm}$, salt $(2.6 \%)$, black 
pepper $(0.4 \%)$, starter cultures, and preservatives were added to the mixture (E301 sodium ascorbate: $0.050 \mathrm{Kg} / \mathrm{q}$ of meat; E252 - potassium nitrate: $0.0020 \mathrm{Kg} / \mathrm{q}$ of meat). The products were dried in a drying room at progressively decreasing temperature, from $23^{\circ}$ to $17^{\circ} \mathrm{C}$, and relative humidity $(\mathrm{RH})$ progressively increasing from 40 to $80 \%$ and then ripened in conditioned rooms at $14^{\circ} \mathrm{C}$ and $80 \% \mathrm{RH}$ for 45 days. Ten salamis per group were collected at the beginning of processing phases (T0) and after 7 (T1), 20 (T2) and 45 (T3) days of ripening and then transferred to the laboratory for the following microbiological and physic-chemical analysis: total viable count (TVC) on Plate Count Agar (PCA; CM0325, Oxoid, Basingstoke, UK) aerobically incubated at $30^{\circ} \mathrm{C}$ for $48 \mathrm{~h}$; Enterobacteriaceae count using Violet Red Bile Glucose Agar (VRBG; CM1082, Oxoid) aerobically incubated at $37^{\circ} \mathrm{C}$ for 24h; enumeration of Enterococcus spp. on Slanetz Bartley (4020472, Biolife) with 2,3,5-Triphenyltetrazolium chloride $1 \%$ solution (42111801, Biolife), incubated at $37^{\circ} \mathrm{C}$ for $48 \mathrm{~h}$; coagulase negative and positive staphylococci were enumerated on Baird Parker agar (4011162, Biolife) with Rabbit Plasma Fibrinogen Supplement II (423102, Biolife) incubated at $37^{\circ} \mathrm{C}$ for 48 $\mathrm{h}$; Lactobacillus spp. were counted on de Man, Rogosa and Sharpe (MRS) agar (CM0361, Oxoid) anaerobically incubated at $37^{\circ} \mathrm{C}$ for 48 ; Lactococcus spp. on M17 agar (CM0785, Oxoid) aerobically incubated at $37^{\circ} \mathrm{C}$ for $48 \mathrm{~h}$. After counting, the data were reported in Log Colony Forming Units (cfu)/g and the mean and standard deviation were calculated; presence of Salmonella spp. and Listeria monocytogenes were tested using the criteria set by ISO 6579 (ISO, 2004) and ISO 11290-1 (ISO, 2005) respectively; water activity $\left(\mathrm{a}_{\mathrm{w}}\right)$ was determined through an AquaLab CX-3 (Decagon Pulman, WA, USA); $\mathrm{pH}$ determination using a penetrating electrode connected to a portable pHmeter (Mod SG2, Mettler Toledo AG, Schwerzenbach, $\mathrm{CH}$ ); colour coordinates (CIE, 1986). Only at the end of the ripening period (T3), the samples were sliced and immediately analysed for the following determination: chemical composition (AOAC, 1990); total antioxidant capacity using the oxygen radical absorbance capacity method $\left(\mathrm{ORAC}_{\mathrm{FL}}\right)$ based on the fluorescence decay rate of a probe in the presence of a radical oxygen species $\left(\mathrm{ROO}^{\circ}\right)$ compared with a reference standard (Trolox: 6-hydroxy-2,5,7,8-tetramethylchroman-2-carboxylic acid, SigmaAldrich, Steinheim, Germany), as reported by Branciari et al., 2015b; lipid oxidation assessed using the thiobarbituric reactive substances test (TBARS) according to Tarladgis et al. (1960) and values were expressed as $\mathrm{mg}$ malondialdehyde (MDA) $/ \mathrm{kg}$ salami; for the determination of total phenolic content (TPC), the extraction of polyphenols was carried out using method described by Branciari et al., 2015b with some modification: $1 \mathrm{~g}$ of sample was homogenised with $20 \mathrm{~mL}$ of ethanol $80 \%$ $(\mathrm{w} / \mathrm{v})$, the homogenate was vortexed and centrifuge for $30 \mathrm{~min} 6000 \mathrm{rpm}$ at $35{ }^{\circ} \mathrm{C}$. For evaluating the phenolic content using the Folin-Ciocalteu method (Singleton et al., 1999) $20 \mu \mathrm{l}$ of the surnatant were transferred into tube containing $1.58 \mathrm{~mL}$ of $\mathrm{H}_{2} \mathrm{O}_{2}$, $100 \mu \mathrm{L}$ of Folin-Ciocalteu phenol reagent (Sigma-Aldrich, St. Louis, MO, USA) was added and mixed. $20 \%$ (w/v) of $\mathrm{Na}_{2} \mathrm{CO}_{3}$ solution $(300 \mu \mathrm{L})$ was added and mixed. The solution was immediately transferred to an incubator and leave at $40^{\circ} \mathrm{C}$ for $30 \mathrm{~min}$. The absorbance of the sample was measured at $765 \mathrm{~nm}$ using an Ultrospec 2100 pro UV/visible spectrometer (Amersham Pharmacia Biotech, Buckinghamshire, UK). For the quantitative determination of TPC, a Gallic acid (Sigma-Aldrich, St. Louis, MO, USA) standard calibration curve $\left(\mathrm{y}=0.0011 \mathrm{x}+0.023 \mathrm{R}^{2}=0.9998\right)$, corresponding to a concentration range of $0.05-0.75 \mathrm{mg} / \mathrm{mL}$. The TPC concentration was expressed as mg gallic acid equivalents (GAE) per g. After 45 days (T3), when Fabriano salamis were ready to be commercialized, in line with standard production methods, a series of consumer tests were performed at the Department of Veterinary Medicine, University of Perugia. Consumers were asked to complete a questionnaire including information regarding their age, sex and frequency of salami consumption (Branciari et al., 2012). The consumer tests were performed in three sessions under different conditions (blind, expected and informed), one week apart. For each session, 95 regular salami consumers (aged 20-60, 45 females and 50 males) were used (regular consumers were those who had a consumption frequency of at least once every two weeks). A practicing session was performed before the test to allow consumers to become familiar with the use of a nine point hedonic scale (from 1 , dislike extremely to 9, like extremely). In the first session, 1 sample/group was monadically served on white plastic plates identified by three random digit codes. Consumers received no information (blind experimental condition) and were asked to rate sensory attributes using the nine-point hedonic scale for appearance, texture, taste, and overall liking. In the second session, the participants were asked to assess on the same hedonic scale their liking expectation from salami (expectation test) when given the following information regarding animal diet: i) salami from pigs fed a standard diet and ii) salami from pigs fed a standard diet enriched with oregano extract, a natural antioxidant with potential positive effect on the product. In the third session the participants rated the samples under informed condition as already performed in blind test, but in this case samples were accompanied by the same information provided for the expectation test on animals dietary treatments.

The data were analysed using Statview (SAS Institute inc., Cary, NC, USA) program. The dietary effects on the same sampling time was evaluated using the unpaired t-test and the differences of the means were considered to be significant when $\mathrm{P}<0.05$.

\section{Results}

The results of the microbiological analysis performed on Fabriano salami at each time considered are reported in Figure 1. The trend of microbial flora was consistent between groups during the whole ripening period. No Salmonella spp. and L. monocytogenes were isolate from the samples and coagulase positive staphylococci were below the limit of detection $(<\log 2 \mathrm{cfu} / \mathrm{g})$ since T0. Furthermore, also chemical composition, $\mathrm{a}_{\mathrm{w}}$ and $\mathrm{pH}$ values did not differ $(\mathrm{P}>0.05)$ between groups (Tables 1 and 2). As for the colour parameters, no significant

Table 1. $\mathrm{pH}$ and aw in CTRL and OR Fabriano salami at different time of ripening. Means \pm standard deviation.

\begin{tabular}{|c|c|c|c|c|}
\hline \multirow{2}{*}{ Ripening days } & \multicolumn{2}{|c|}{$\mathrm{pH}$} & \multicolumn{2}{|c|}{$a_{w}$} \\
\hline & CTRL & OR & CTRL & OR \\
\hline 0 & $5.89 \pm 0.04$ & $5.95 \pm 0.07$ & $0.954 \pm 0.009$ & $0.954 \pm 0.009$ \\
\hline 7 & $5.20 \pm 0.08$ & $5.24 \pm 0.04$ & $0.946 \pm 0.011$ & $0.948 \pm 0.003$ \\
\hline 20 & $5.13 \pm 0.03$ & $5.21 \pm 0.09$ & $0.931 \pm 0.015$ & $0.931 \pm 0.005$ \\
\hline 45 & $5.47 \pm 0.02$ & $5.45 \pm 0.02$ & $0.897 \pm 0.008$ & $0.896 \pm 0.002$ \\
\hline
\end{tabular}

CTRL: salami made with pigs fed with standard diet; OR: salami made with pigs fed with diet supplemented with oregano extract. 
differences in the $\mathrm{L}^{*}$ values between the groups at each time considered (data not reported) were recorded, while after 20 days of ripening (T2) the $a^{*}$ values for the OR salami were higher $(\mathrm{P}<0.01)$ compared to CTRL samples $\left(\mathrm{OR}_{\mathrm{T} 2}: 16.88 \pm 0.91\right.$ vs $\mathrm{CTRL}_{\mathrm{T} 2}: 14.35 \pm 1.12 ; \mathrm{OR}_{\mathrm{T} 3}: 15.86 \pm 0.86 v \mathrm{~s}$ $\left.\mathrm{CTRL}_{\mathrm{T} 3}: 12.96 \pm 1.26\right)$, which were also yellower ( $b^{*}$ value, $\mathrm{P}<0.01$ ) at the end of ripening period (OR: $7.78 \pm 0.35$ vs CTRL: $9.56 \pm 0.80)$. Furthermore, the lipid oxidation (TBARS values) of meat was lower $(\mathrm{P}<0.01)$ in $\mathrm{OR}$ than in the CTRL group (Table 2). Differences between groups were recorded also for antioxidant activity and polyphenols content as evidenced by $\mathrm{ORAC}_{\mathrm{FL}}$ and TPC values, higher $(\mathrm{P}<0.05)$ in OR then CTRL salami (Table 2). With respect to sensorial analysis, the results of consumer tests performed under blind, informed and expectation conditions are reported in Table 3 and Figure 2. The two groups of salami received the same scores in the blind test, whereas when the samples were accompanied by a label (informed condition), the consumers gave a higher $(\mathrm{P}<0.05)$ score to OR salami.

\section{Discussion}

The improvement of meat and meat products hygienic characteristics due to animal diet supplementation with plant extracts reported by several authors (Bañón et al., 2012; Nieto et al., 2010; Serrano et al., 2014) has not been recorded in this study. This result is in agreement with pre-

vious studies from the same team in which natural preservatives feed supplementation did not affect microbiological characteristics of animal food product (Branciari et al.

Table 2. Chemical composition, total phenolics content (TPC), thiobarbituric reactive substances (TBARS) and total antioxidant capacity $\left(\mathrm{ORAC}_{\mathrm{FL}}\right)$ in CTRL and OR Fabriano salami at 45 days of ripening. Means \pm standard deviation.

\begin{tabular}{lcc} 
& CTRL & OR \\
Moisture (\%) & $34.06 \pm 0.68$ & $33.69 \pm 0.76$ \\
Fat (\%) & $37.61 \pm 0.94$ & $37.31 \pm 1.06$ \\
\hline Protein (\%) & $23.48 \pm 0.64$ & $24.10 \pm 0.93$ \\
Ash (\%) & $4.85 \pm 0.14$ & $4.90 \pm 0.17$ \\
\hline TPC (mg GAE/g) & $1.35 \pm 0.16^{\mathrm{a}}$ & $1.57 \pm 0.13^{\mathrm{b}}$ \\
TBARS (mg MDA/kg) & $1.21 \pm 0.18^{\mathrm{a}}$ & $0.98 \pm 0.14^{\mathrm{b}}$ \\
\hline ORAC $_{\text {FL }}(\mu \mathrm{mol} \mathrm{TE} / \mathrm{g})$ & $17.26 \pm 1.93^{\mathrm{a}}$ & $20.46 \pm 2.53^{\mathrm{b}}$ \\
\hline
\end{tabular}

CTRL: salami made with pigs fed with standard diet; OR: salami made with pigs fed with diet supplemented with oregano extract; different letters within a same row differ significantly $(\mathrm{P}<0.05)$.

Table 3. Blind and informed liking scores for CTRL and OR Fabriano salami.

\begin{tabular}{lcccc} 
Item & \multicolumn{2}{c}{ Blind } & \multicolumn{2}{c}{ Informed } \\
& CTRL & OR & CTRL & OR \\
Appearance & $7.05 \pm 1.19$ & $6.74 \pm 1.26$ & $6.29 \pm 1.07^{\mathrm{a}}$ & $7.09 \pm 0.80^{\mathrm{b}}$ \\
Texture & $6.75 \pm 1.13$ & $6.76 \pm 1.09$ & $6.33 \pm 1.02^{\mathrm{a}}$ & $6.84 \pm 0.92^{\mathrm{b}}$ \\
\hline Taste & $7.06 \pm 1.18$ & $6.69 \pm 1.02$ & $6.15 \pm 0.93^{\mathrm{a}}$ & $6.87 \pm 0.75^{\mathrm{b}}$ \\
Overall liking & $6.96 \pm 1.02$ & $6.64 \pm 1.14$ & $6.49 \pm 0.96^{\mathrm{a}}$ & $7.15 \pm 0.82^{\mathrm{b}}$ \\
\hline
\end{tabular}

CTRL: salami made with pigs fed with standard diet; OR: salami made with pigs fed with diet supplemented with oregano extract; results are the mean values \pm standard deviation of 95 consumers for each test (Blind and Informed); for each test different letters within a row mean differences $(\mathrm{P}<0.05)$.
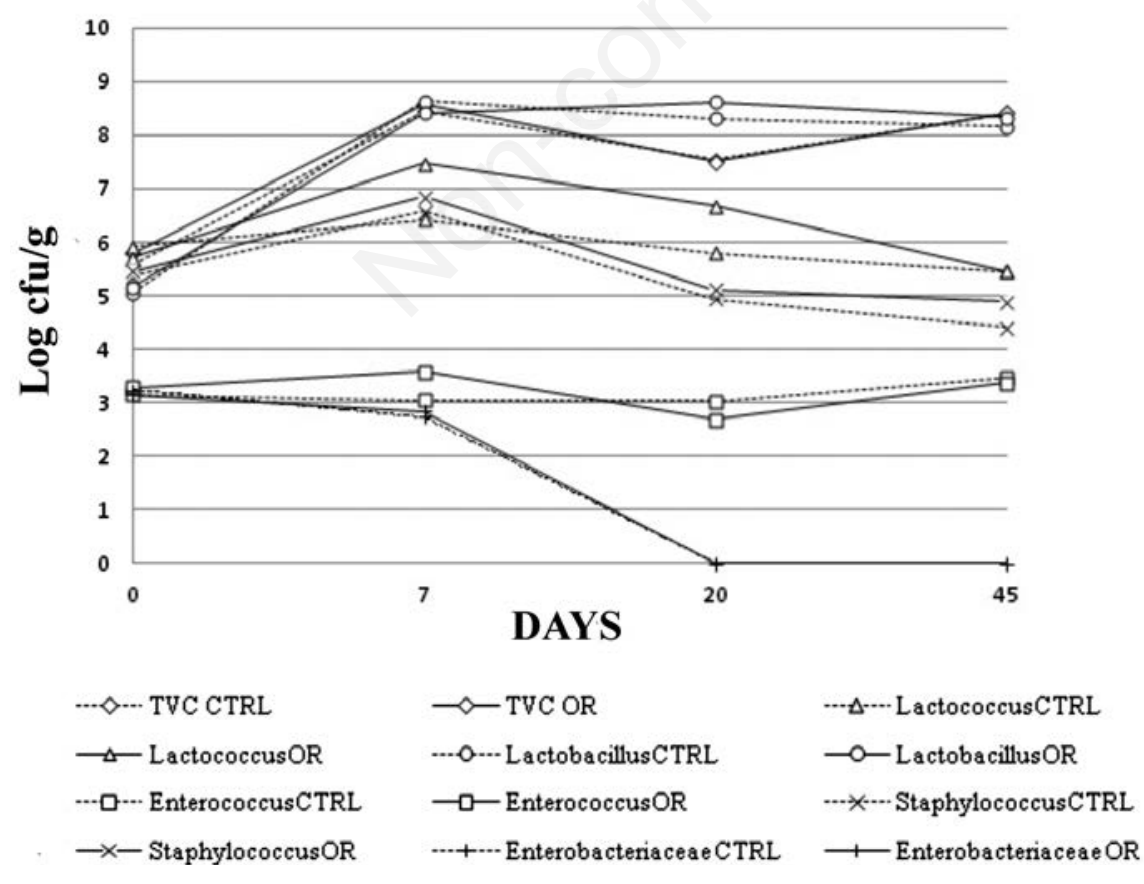

Figure 1. Microbial dynamics in CTRL and OR Fabriano salami at different time of ripening. CTRL: salami made with pigs fed with standard diet; OR: salami made with pigs fed with diet supplemented with oregano extract.

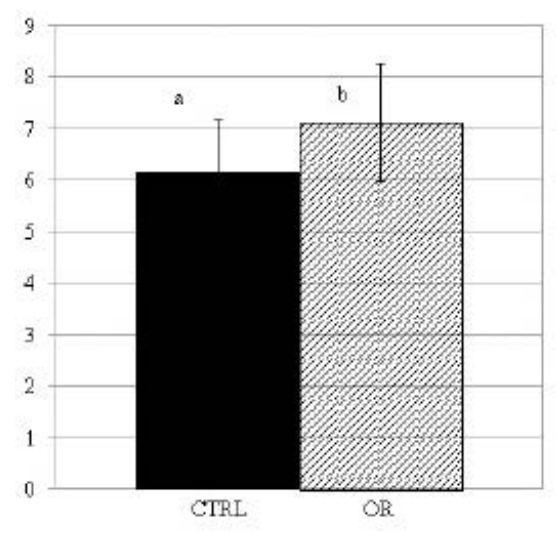

Figure 2. Expected overall liking scores for CTRL and OR Fabriano salami. CTRL: salami made with pigs fed with standard diet; OR: salami made with pigs fed with diet supplemented with oregano extract; results are the mean values of 95 consumers; different letters represent significant differences between groups $(\mathbf{P}<\mathbf{0 . 0 5})$. 
2015a, 2015b, 2016; Ranucci et al., 2013, 2015). Moreover, the antimicrobial activity of these substances assessed in vitro, or when directly added to food, is widely demonstrated in literature (Chaves-López et al., 2015; Fasolato et al., 2015; Miraglia et al., 2016), even though the antimicrobial activity is related to the plant extract concentration which could affect sensory characteristics of the product (Giarratana et al., 2013, 2016). The use of natural substances in vivo as feed additives could avoid unpleased organoleptic traits in the product, however the antimicrobial efficacy is controversial. Probably other factors, such as primary production hygiene, process hygiene and process technology exert a great influence on microbial characteristics of the product. The dietary integration with oregano extract did not affect starter bacteria growth, therefore the salami from both experimental groups showed equivalent microbial evolution and fermentative processes. Neither $\mathrm{pH}$ and $\mathrm{a}_{\mathrm{w}}$ have been influenced by diet and at the end of ripening values were in line with those typical for this type of products. Nevertheless, in this study the introduction of bioactive substances in the diet was responsible for the effects on the other chemical and physical parameters such as oxidative stability and the colour. Lower content of MDA was found in OR salami, denoting an antioxidant effect exerted on the lipidic component (Table 2). Also the increase in $b^{*}$ values for CTRL salami could be a consequence of the oxidative reactions of lipids, which, not protected from dietary polyphenols, became more yellowish (Nieto et al., 2010). An antioxidant effect has also been registered for myoglobin, responsible for the red colour of meat, as highlighted by the higher values of $\mathrm{a}^{*}$ in OR salami compared to CTRL ones. These results are in agreement with several authors, claiming that polyphenols may delay oxidation of fats and myoglobin, therefore stabilizing meat colour (Balentine et al., 2006; Luciano et al., 2011; Nieto et al., 2010; Ranucci et al., 2015; Ripoll et al., 2011). Apart from improving the oxidative status, the presence of oregano in the diet has significantly increased the polyphenolic concentration in OR salami, enhancing antioxidant power (Table 2). These results confirm that dietary inclusion of bioactive substances could represent an effective solution for the achievement of enriched meat and meat products (Moñino et al., 2008), increasing their nutritional value. Valenzuela et al. (2003) reports that the consumption of meat products rich in natural antioxidants reinforce the endogenous antioxidant efficacy against oxidative stress and ROS-induced tissue damage and degen- erative diseases. With respect to sensorial analysis, consumers were positively affected by the information, giving a higher score to OR samples for all attributes. Furthermore, consumers showed a higher expectation for the OR salami compared with the CTRL ones. Results regarding consumer behaviour obtained in the present study are in line with Branciari et al. (2016), who showed how the effect of the label modifies consumers acceptability of the products.

\section{Conclusions}

The integration of pig diet with oregano extract can improve some quality traits of Fabriano salami such as the lipid oxidation, the colour and the polyphenolic content. Furthermore the addition of such natural compound has positively affected consumer's perception.

\section{References}

Akarpat A, Turhan S, Ustun NS, 2008. Effects of hot-water extracts from myrtle, rosemary, nettle and lemon balm leaves on lipid oxidation and color of beef patties during frozen storage. $\mathrm{J}$ Food Process Preserv 32:117-132.

AOAC, 1990. Official methods of analysis. $15^{\text {th }}$ ed. Association of Official Analytical Chemists ed., Washington, DC, USA.

Balentine CW, Crandalla PG, O'Bryana CA, Duonga DQ, Pohlmanb FW, 2006. The pre-and post-grinding application of rosemary and its effects on lipid oxidation and color during storage of ground beef. Meat Sci 73:413-421.

Bañón S, Méndez L, Almela E, 2012. Effects of dietary rosemary extract on lamb spoilage under retail display conditions. Meat Sci 90:579-83.

Burt S, 2004. Essential oils: their antibacterial properties and potential applications in foods - a review. Int $\mathrm{J}$ Food Microbiol 94:223-53.

Branciari R, Balzano M, Pacetti D, Trabalza-Marinucci M, Della Casa G, Miraglia D, Capotorti A, Frega NG, Ranucci D, 2016. Dietary CLA supplementation of pigs confers higher oxidative stability to Ciauscolo and Fabriano salami produced from their meat with no negative impact on the physicochemical, microbiological and sensorial characteristics. Eur J Lipid Sci Technol 118:1475-1485.

Branciari R, Ranucci D, Miraglia D, Urbani
S, Esposto S, Servili M, 2015a. Effect of dietary treatment with olive oil byproduct (olive cake) on physicochemical, sensory and microbial characteristics of beef during storage. Ital J Food Safety 4:225-229.

Branciari R, Ranucci D, Trabalza Marinucci M, Codini M, Orrù M, Ortenzi R, Forte C, Ceccarini MR, Valiani A, 2015b. Evaluation of the antioxidant properties and oxidative stability of Pecorino cheese made from the raw milk of ewes fed Rosmarinus officinalis L. leaves. Int J Food Sci Tech 50:558-65.

Branciari R, Valiani A, Trabalza-Marinucci M, Miraglia D, Ranucci D, Acuti G, Esposto S, Mughetti L, 2012. Consumer acceptability of ovine cheese from ewes fed extruded linseed-enriched diets. Small Ruminant Res 106:43-48.

CIE, 1986. Colorimetry 15.2. Commission Internationale de l'Eclairage Publ., Vienna, Austria.

Chaves-López C, Serio A, Mazzarrino G, Martuscelli M, Scarpone E, Paparella A, 2015. Control of household mycoflora in fermented sausages using phenolic fractions from olive mill wastewaters Int J Food Microbiol 207:49-56.

European Parliament and the Council of the European Union (2010). Directive 2010/63/ EU of the European Parliament and of the Council of 22 September 2010 on the protection of animals used for scientific purposes. Off J Eur Union 276.

Fasolato L, Cardazzo B, Balzan S, Carrao L, Taticchi A, Montemurro F, Novelli E, 2015. Minimum bactericidal concentration of phenols extracted from oil vegetation water on spoilers, starters and food-borne bacteria. Ital J Food Safety 4:4519.

Giarratana F, Muscolino D, Beninati C, Ziino G, Giuffrida A, Panebianco A, 2013. Effects of thyme and rosemary essential oils on the microbiology and shelf life of Italian Mortadella. Fleischwirtschaft 93:183-187.

Giarratana F, Muscolino D, Ragonese C, Beninati C, Sciarrone D, Ziino G, Mondello L, Giuffrida A, Panebianco A, 2016. Antimicrobial activity of combined thyme and rosemary essential oils against Listeria monocytogens in Italian mortadella packaged in modified atmosphere. J Essent Oil Res 2016:1-8.

Huang B, He J, Ban X, Zeng H, Yao X, Wang Y, 2011. Antioxidant activity of bovine and porcine meat treated with extracts fromedible lotus (Nelumbo nucifera) rhizome knot and leaf. Meat Sci 87:46-53.

Jiang J, Xiong YL, 2016. Natural antioxi- 
dants as food and feed additives to promote health benefits and quality of meat products: A review. Meat Sci 120:107117.

Luciano G, Vasta V, Monahan FJ, LópezAndrés P, Biondi L, Lanza M, Priolo A, 2011. Antioxidant status, colour stability and myoglobin resistance to oxidation of longissimus dorsi muscle from lambs fed a tannin-containing diet. Food Chem 124:1036-42.

Miraglia D, Esposto S, Branciari R, Urbani S, Servili M, Perucci S, Ranucci D, 2016. Effect of a Phenolic extract from olive vegetation water on fresh salmon steak quality during storage. Ital J Food Safety 5:224-228.

Moñino I, Martinez C, Sotomayor JA, Lafuente A, Jordan MJ, 2008. Polyphenolic transmission to Segureño lamb meat from ewes'diet supplemented with the distillate from rosemary (Rosmarinus officinalis) leaves. J Agr Food Chem 56:3363-7.

Nieto G, Diaz P, Bañón S, Garrido MD, 2010. Dietary administration of ewe diets with a distillate from rosemary leaves (Rosmarinus officinalis L.): influence on lamb meat quality. Meat Sci 84:23-9.

Ranucci D, Branciari R, Acuti G, Della Casa G, Trabalza-Marinucci M, Miraglia D, 2013. Quality traits of Ciauscolo salami made from meat of pigs fed rosemary extract with enriched diet. Ital J Food Safety 2:49-52.

Ranucci D, Miraglia D, Trabalza-Marinucci M, Acuti G, Codini M, Ceccarini MR, Forte C, Branciari R, 2015. Dietary effects of oregano (Origanum vulgaris L.) plant or sweet chestnut (Castanea sativa Mill.) wood extracts on microbiological, chemico-physical characteristics and lipid oxidation of cooked ham during storage. Ital J Food Safety 4:216-219.

Rea S, Ricciutelli M, Pacifici L, Stocchi R, Loschi AR, 2005. Biogenic amine concentration in "Lardellato" salami, a traditional product of central Italy, during ripening. Ital J of Food Sci 2:211-220.

Ripoll G, Joy M, Muñoz F, 2011. Use of dietary vitamin $\mathrm{E}$ and selenium $(\mathrm{Se})$ to increase the shelf life of modified atmosphere packaged light lamb meat. Meat Sci 87:88-93.
Serrano R, Jordan MJ, Bañón S, 2014. Use of dietary rosemary extract in ewe and lamb to extendthe shelf life of raw and cooked meat. Small Ruminant Res 116:144-52.

Singleton VL, Orthofer R, LamuelaRaventós RM, 1999. Analysis of total phenols and other oxidation substrates and antioxidants by means of folin-ciocalteu reagent. Meth Enzymol 299:152178.

Srinivasan K, 2014. Antioxidant potential of spices and their active constituents. Food Sci Nut 54:352-372.

Tarladgis BG, Watts BM, Yonathan M, 1960. Distillation method for the determination of malonaldehyde in rancid foods. J Am Oil Chem Soc 37:44-8.

Valenzuela A, Sanhueza J, Nieto S, 2003. Natural antioxidants in functional foods: From food safety to health benefits. Grasas Aceites 54:295-303.

Zheng W, Wang SY, 2001. Antioxidant activity and phenolic compounds in selected herbs. J Agr Food Chem 49: 5165-70. 